Entrevista - Diálogos Midiológicos 44

\title{
Mídia, comunidade e a pedagogia da mudança social ${ }^{1}$
}

Media, community and social change pedagogy

Medios, comunidad y pedagogía del cambio social

DOI: https://doi.org/10.1590/1809-58442020312

Vicki Mayer ${ }^{1}$

https://orcid.org/0000-0002-7812-3591

\section{Entrevista concedida a:}

Veneza Mayora Ronsini ${ }^{2}$

http://orcid.org/0000-0002-8669-3148

\section{Laura Roratto Foletto ${ }^{2}$}

https://orcid.org/0000-0002-0205-1229

\section{Marco Marão ${ }^{2}$}

https://orcid.org/0000-0003-3036-1088

\section{Rafael Ferreira Medeiros ${ }^{2}$}

https://orcid.org/0000-0002-0327-3982

\section{Mauricio Rebellato ${ }^{2}$}

https://orcid.org/0000-0003-0244-1849

\section{Lucas Reinehr ${ }^{3}$}

https://orcid.org/0000-0003-3968-4940

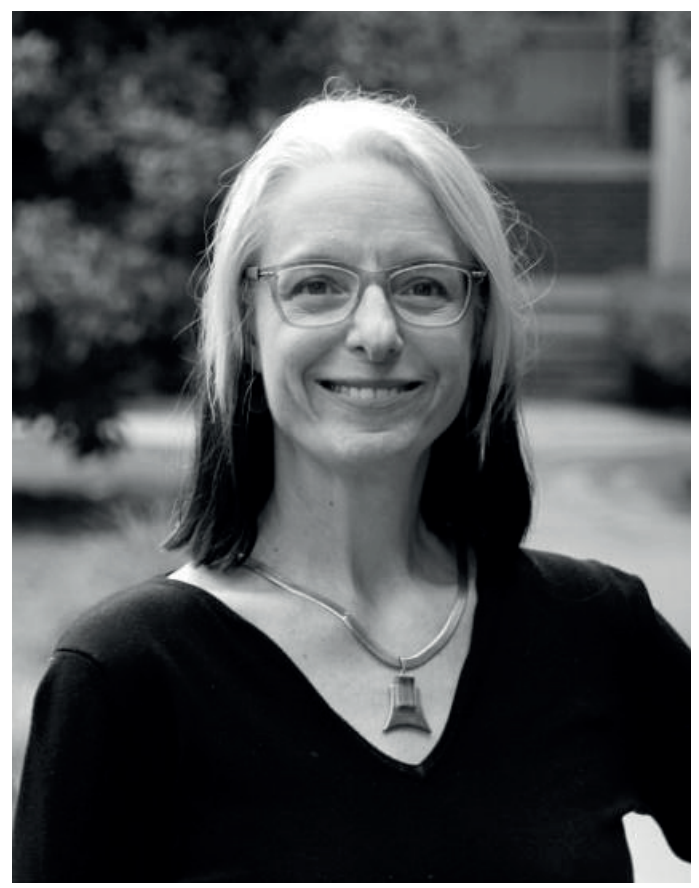

Fonte: Website da Tulane University ${ }^{2}$

${ }^{1}$ (Tulane University, School of Liberal Arts, Department of Communication. Nova Orleans - Estados Unidos).

${ }^{2}$ (Universidade Federal de Santa Maria, Centro de Ciências Sociais e Humanas, Programa de Pós-Graduação em Comunicação. Santa Maria - RS, Brasil).

${ }^{3}$ (Universidade Federal de Santa Maria, Centro de Ciências Sociais e Humanas, Departamento de Comunicação. Santa Maria - RS, Brasil).

1 A entrevista com a professora Vicki Mayer foi realizada pelos integrantes do Grupo de Pesquisa Usos Sociais da Mídia durante a missão da pesquisadora no Programa de Pós-Graduação em Comunicação da Universidade Federal de Santa Maria (UFSM), financiada pelo programa de Internacionalização CAPES/PrInt - Edital 41/2017. A Dra Vicki Mayer ministrou o Seminário "Mídias e identidades”, realizado entre 2 e 5 de outubro de 2019 na UFSM, o qual foi coordenado pela profa Dra. Veneza Mayora Ronsini e organizado em parceria com os grupos de pesquisa Estudos de Jornalismo (profa. Dra. Márcia Franz Amaral) e Estudos e Projetos em Comunicação e Estudos Culturais (profa. Dra. Ana Carolina Escosteguy).

2 Disponível em: https://liberalarts.tulane.edu/departments/communication/people/dr-vicki-mayer. Acesso em: 10 set. 2020. 
Vicki Mayer é pesquisadora e professora titular no Departamento de Comunicação da Tulane University (Universidade Tulane), em Nova Orleans, nos Estados Unidos (EUA), onde ministra as disciplinas de Análise de Mídia, Análise de Tecnologias, Jornalismo Alternativo e História da Mídia. Em 1997, formou-se como Mestre em Comunicação pela Universidade da Califórnia, em San Diego, EUA. Em 2000, formou-se como Doutora em Comunicação pela mesma instituição. Visando examinar os modos como a mídia e a comunicação conformam trabalhadores e cidadãos, ela realiza pesquisas sobre a mídia e as indústrias da comunicação, suas economias políticas, infraestruturas e suas culturas organizacionais de trabalho. Entre seus interesses de pesquisa, incluem-se ainda: comunidades e mídia alternativa; mídia e identidades; estudos de produção midiática; estudos de audiência e consumo de mídia; comunicação e desenvolvimento regional. Suas publicações incluem três livros autorais, três volumes editados e 33 artigos em revistas científicas.

Através de uma pedagogia participativa, ela tem por objetivo possibilitar a expressão de vozes estudantis e comunitárias na esfera pública, estimulando a preservação digital e o acesso aberto ao patrimônio cultural local. Assim, ela incentiva seus alunos a desenvolverem, de modo colaborativo, pesquisas sobre produções culturais e expressões criativas. Essas atividades colaborativas coordenadas pela professora resultaram no projeto MediaNola, um website que buscava dar visibilidade às contribuições de pessoas comuns para a cultura de Nova Orleans e suas representações. O mais recente projeto criado por ela com a colaboração dos seus alunos é ViaNolaVie ${ }^{3}$, uma revista digital desenvolvida ao longo de dois anos junto a estudantes e habitantes locais, dedicada à divulgação de trabalhos realizados por estudantes, escritores e artistas locais.

Nesta entrevista, Vicki Mayer fala sobre a possibilidade de mudança social através de práticas pedagógicas associadas à mídia. Para ela, um dos caminhos para a superação da precariedade enfrentada pelas comunidades latino-americanas em relação ao acesso às tecnologias digitais de comunicação começa nas universidades públicas, por meio da implementação de um circuito pedagógico que construa informação e as devolva à comunidade, pois, de acordo com ela, as tecnologias só são verdadeiramente populares quando consumidas em um processo coletivo. Por esta razão, ela ressalta que o processo de construção de um projeto colaborativo, a exemplo do MediaNola, é mais importante que o produto final em si.

Lançando luz a noções como pedagogia participativa, comunicação participativa, mídia comunitária, mídia de Movimentos Sociais, ideologia e hegemonia, Vicki Mayer nos traz, ao longo desta entrevista, apontamentos para pensarmos as potencialidades da comunicação diante da atual onda fundamentalista que marca a conjuntura sociopolítica tanto dos EUA quanto do Brasil.

3 Disponível em: https://www.vianolavie.org/. Acesso em: 7 set. 2020. 
Revista Intercom - Através do projeto MediaNola, você fala da produção de uma experiência pedagógica desenvolvida nos meios digitais. No Brasil, a infraestrutura de internet em comunidades periféricas e de zonas rurais é limitada e, quando essa infraestrutura é satisfatória, a internet é usada para o entretenimento, principalmente pelas crianças e jovens. Oito em cada dez crianças e jovens dizem consumir conteúdos ligados ao entretenimento, segundo o Comitê Gestor da Internet no Brasil (2018) ${ }^{4}$. Por sua vez, Orozco Gómez (2011) afirma que menos de $10 \%$ de crianças e adolescentes que são usuários da internet nos países latino-americanos são produtores de conteúdo. Tendo isso em vista, como incentivar o uso da internet por jovens da periferia e das zonas rurais no Brasil para que se avance nas preocupações de interesse das comunidades e para que se reduzam hierarquias e desigualdades sociais?

Vicki Mayer - Essa é uma grande questão. O projeto MediaNola foi mesmo desenvolvido no contexto da educação universitária. A ideia era que as pessoas que frequentam a universidade compartilhassem de volta com a comunidade local os assuntos interessantes que estão aprendendo, porque nós consideramos que a universidade é o local de pesquisa sobre a comunidade. A ideia não é trabalhar com crianças com menos de 17 ou 18 anos que estão entrando na universidade, mas a sua ideia é interessante porque devemos nos perguntar: quem está na universidade? Essa semana que eu estive aqui em Santa Maria, observei que muitas pessoas na universidade vêm de áreas rurais, de periferias. Essa é a vantagem das universidades públicas: elas podem criar projetos nos quais os estudantes evitem pensar como caixas vazias a serem preenchidas com informação, mas, sim, encontrando maneiras de usar a informação que eles têm sobre a comunidade. Acredito que construir a informação e devolvê-la para a comunidade para as futuras gerações criaria um circuito pedagógico e essa seria uma boa maneira de se usar a tecnologia digital. A questão do acesso sempre é pertinente, mas a universidade tem o papel de fornecer acesso, fornecer infraestrutura, fornecer espaços. Por exemplo, o que compreendo na sua pergunta é que não é suficiente alguém vir para a universidade, estudar e escrever de uma maneira popular para compartilhar de volta com a comunidade. Isso também se torna um desafio, eu diria, de planejamento, de descobrir como, na comunidade, se pode ter acesso ao site produzido na universidade. Também podemos ver, por exemplo, muitos projetos criativos pelo mundo inteiro, como o caso das conexões piratas de internet. Na Argentina, existem pessoas que sobem na cobertura de prédios para distribuir conexões de Wi-Fi que todos possam usar. Sempre há como se pensar em soluções para esses problemas de comunicação: algumas delas envolvem instituições, a universidade, as companhias de telecomunicações, o governo; algumas delas vão ter que ser "soluções criativas" que funcionem fora das instituições, mas com pessoas inseridas nessas instituições, porque, para começar uma nova plataforma digital, você precisa ter uma base na educação e uma conexão com alguma instituição. Pensar em redes que conectem a comunidade e a universidade por meio de projetos digitais

4 Disponível em: https://www.cgi.br/noticia/releases/cresce-numero-de-criancas-e-adolescentes-que-buscam-noticias-na-internet-aponta-cetic-br/. Acesso em: 7 set. 2020. 
seria um jeito de pensar no que o MediaNola poderia contribuir como uma ideia, como um conceito para a juventude brasileira.

Revista Intercom - Como diz o Orozco Gómez (2011), não é que não vamos mais ter entretenimento, mas que $90 \%$ dos usos de mídia por crianças e adolescentes nos países latinoamericanos são voltados para o entretenimento.

Mayer - Sim, temos que aproveitar as pessoas onde elas estão, onde elas têm acesso. Mas imagine se estivéssemos iniciando um projeto onde as pessoas da universidade que vêm dessas comunidades estivessem compartilhando de volta a informação que elas aprenderam na universidade com seus irmãos e irmãs mais novos, com seus primos, tios, tias... essas pessoas teriam acesso a outros tipos de conteúdo, não só entretenimento. Além disso, não quero necessariamente fazer uma divisão entre informação e entretenimento. Os dois podem ser muito eficazes quando combinados, apenas estou considerando o que essa estatística sugere.

Revista Intercom - Como a comunicação pode ser usada pelos jovens brasileiros pobres para que eles entendam que podem ser agentes de mudança social da realidade em que vivem? Mayer - O passo mais crítico ao se pensar sobre a comunicação e justiça social... "justiça social” é a palavra do momento, o termo que usamos bastante agora nos EUA. Queremos que a mudança social crie uma sociedade mais justa e igual. Nesse sentido, é importante pensarmos em uma comunicação na qual as pessoas participem em seus próprios termos, e muito da comunicação tem sido (pensado) à luz da teoria da modernização, que foi postulada na década de 1950 com a perspectiva de que "vamos modernizar aquelas pessoas pobres trazendo a elas acesso à mídia de massa e treinando-as para serem profissionais como nós”. Na América Latina, África e no sudeste asiático, a ideia a respeito da comunicação era a de que a mudança social viria porque no primeiro mundo, ou nós que estamos nos centros, no Rio Grande do Sul e em São Paulo, iríamos até aquelas pessoas pobres e levaríamos as ferramentas para a mudança delas. O que aconteceria se alguém chegasse até você e dissesse "vem cá, olhe para mim, eu vou tirar você da sua condição de pobreza”? A pessoa provavelmente responderia “saia daqui”. Elas sabem disso. As faculdades de Educação estão usando esse método de se vincular à comunidade, identificando quais temas são importantes para as pessoas da comunidade, sejam elas jovens ou velhas, criando espaços para uma comunicação aberta em vez de dizer às pessoas o que elas precisam ter ou fazer. Penso que essas lições, que agora nós compartilhamos como parte de um modelo educacional baseado na comunidade, também são um modelo comunicacional baseado na comunidade.

Revista Intercom - Você menciona, ainda, a relevância do pensamento de Paulo Freire para os pesquisadores interessados em estudos de comunidade e que suas perspectivas têm ressurgido entre os pesquisadores norte-americanos. As preocupações de Freire concentravam-se na "democratização da sociedade (geral) e dentro dela com a democratização da cultura”, e ele “indicou caminhos para a realização desse pleito” (PERUZZO, 2017, p. 3). Peruzzo (2017) 
faz uma aproximação entre algumas das ideias de Freire para uma educação libertadora e a pauta de estudos sobre mídia comunitária no Brasil. Através dessa aproximação, Peruzzo (2017) traz as noções freireanas de democratização da cultura, consciência crítica e educação das massas. Como a abordagem de Peruzzo (2017) sobre as ideias de Freire dialoga com os pesquisadores de mídia comunitária na América do Norte?

Mayer - É curioso, porque cresci lendo Freire nas minhas aulas de Estudos Brasileiros. Eu estava estudando português na década de 1990 e, naquela época, ele era, digamos assim, pouco conhecido fora de centros muito pequenos. As comunidades que estavam lendo culture jamming ${ }^{5}$ eram as mesmas que estavam lendo Saul Alinsky, que era um lutador pelos direitos das comunidades e também um ativista e sindicalista. Seu livro mais famoso era Rules for Radicals (1971). As pessoas que estavam lendo Paulo Freire o faziam ao estudar literatura brasileira ou ao estudar um contexto brasileiro específico, mas o liam, sobretudo, no contexto de um movimento, entre os radicais dos EUA, de reivindicação por diferentes tipos de direitos em seus locais de trabalho, na comunidade, nas artes, (no contexto de) movimentos que começaram na década de 1960 nos EUA, como o movimento promovido pelo Estudantes para uma Sociedade Democrática ${ }^{6}$. Portanto, Paulo Freire não era tão divulgado, digamos. Mais recentemente, ele se tornou requisitado nas leituras das faculdades de Serviço Social. É interessante pensar nisso. As faculdades de Serviço Social escolheram Paulo Freire como alguém que ajudaria a democratizar esferas da comunidade nas quais as instituições querem fazer mudanças e, nesse sentido, Freire é crítico, mas não é radical. Paulo Freire encoraja as pessoas a aprenderem as lições a partir de suas próprias narrativas e de suas próprias histórias. Mas Freire era padre! As lições ainda vêm da Bíblia. Era um jeito de fazer a Bíblia viver através das experiências diárias das pessoas. E isso já era considerado radical durante a ditadura militar no Brasil, mas na Educação e Serviço Social é realmente no sentido de como as pessoas aprendem as lições de participação cívica ou lições que já são parte de instituições através de suas próprias experiências. É interessante que Freire tenha se tornado muito popular e acredito que ele se tornou menos radical nos modos como ele está sendo usado hoje por causa do contexto.

Revista Intercom - O conceito de Comunicação Participativa, abordado por Protz (1991) em “Distinguishing Between 'Alternative' and 'Participatory' Models of Video Production”, pode ser definido como um processo em que pessoas de contextos rurais ou de parcelas mais desfavorecidas da sociedade produzem seu próprio conteúdo midiático. O objetivo não é, necessariamente, produzir materiais de mídia em si, mas usar o processo de produção de

5 Culture jamming é um termo corrente desde os anos 1980 para caracterizar o uso tático da mídia em ações artísticas e lúdicas, através do uso da détournment, técnica que se utiliza da própria linguagem ou retórica da cultura mainstream para criticá-la. Tais ações constituem protestos realizados por múltiplos movimentos sociais anticonsumistas que visam a subversão da cultura midiática hegemônica dos meios massivos. Klein (2002) e Freire Filho (2005) sublinham o seu caráter político, respectivamente, em ações anticorporativas/antipublicitárias e em ações de coletivos de jovens artistas.

6 O movimento Students for a Democratic Society (Estudantes para uma Sociedade Democrática) foi uma organização de ativismo estudantil criada nos EUA durante a década de 1960. O movimento, que lutava por uma "democracia participativa”, foi um dos principais representantes da New Left (Nova Esquerda). 
mídia como forma de capacitar as pessoas "com a confiança, as habilidades e as informações necessárias para resolver seus próprios problemas e fornecer-lhes as informações necessárias", isto é, as "ferramentas de mídia necessárias para articular suas experiências e intenções” (PROTZ, 1991, p. 32), ferramentas para o empoderamento dos sujeitos. Parece um conceito interessante para se pensar outras formas de produção midiática, para além da produção audiovisual. Que outras formas de produção midiática poderiam ser consideradas Comunicação Participativa?

Mayer - Essa é uma pergunta maravilhosa de se fazer atualmente, porque com as mídias sociais, a internet, o YouTube, a produção em celulares, todo mundo hoje é um produtor. Então, de alguma maneira, pode-se dizer, por um lado, que todos estamos fazendo mídia participativa. Ao mesmo tempo, existem duas questões - uma é o limite da criatividade na participação, por exemplo: toda plataforma online tem certas possibilidades, coisas que você pode fazer e coisas que você não pode e isso é muito interessante. Se você tentar criar plataformas comunitárias, terá que decidir os limites de sua própria participação. Quando criamos o MediaNola, queríamos que ele fosse um site tipo o da Wikipedia, mas com mais autoridade em termos do conhecimento que ele oferecia. Mas o gênero da Wikipedia é muito limitador. As maneiras pelas quais você pode falar, as vozes às quais você pode dar espaço, as maneiras pelas quais você avalia diferentes tipos de produção e diferentes tipos de conteúdo são limitadas pelo gênero e pela plataforma. Então, se por um lado somos todos produtores, por outro aceitamos alguns limites quando vamos para a plataforma online, nas quais muitas vezes não somos os únicos a estabelecer os limites em relação ao modo como participamos. De certa forma, se você der uma lanterna a uma criança e um pedaço de papel, ela tem mais liberdade para ser participativa, porque ela tem que inventar o seu próprio conteúdo, com poucas barreiras. Mas aí vem o segundo problema, ligado ao fato de todos sermos participativos e produtores hoje: dizer que todos somos, de certo modo, produtores é, filosoficamente, dizer que nenhum de nós é produtor. Se todos somos produtores, nenhum de nós o é, então as comunidades profissionais, jornalistas, produtores de TV e músicos têm de construir hierarquias para definir o que é um produtor. Tais designações profissionais são classificações que servem para excluir a participação.

Revista Intercom - Você concorda que é mais importante o processo de participar do que o resultado em si? Como você compreende essa ideia?

Mayer - Sim, uma das lições que estão vindo da mídia participativa é que o processo é mais importante do que os fins, os meios acima dos fins, o processo acima do produto, e isso realmente depende do objetivo do projeto. Se você acredita em comunicação comunitária, mídia comunitária, mídia participativa, o objetivo seria a conscientização, valorizar as vozes, legitimar o conhecimento local, preservar a cultura local, e esses processos são mais importantes do que qualquer objeto físico específico resultante desse processo. É por isso que o trabalho social está tão interessado em Freire. É sobre esse processo de conscientização. Ao mesmo tempo, o que aprendemos também é importante. Quando você deposita muita 
energia em fazer um vídeo de uma comunidade, você deve preservar esse vídeo, arquivá-lo, encontrar alguma maneira de cuidar dele como algo precioso. Ele não consegue representar esse processo em sua totalidade, mas é uma lembrança dele.

Revista Intercom - Alguns dos seus estudos são sobre projetos brasileiros de vídeo popular, como a TV Maxambomba. Como podemos ver nas suas e em muitas outras pesquisas, a comunicação popular tem um potencial político ao ajudar pessoas a formarem uma visão de mundo crítica. No Brasil, nossa estrutura da mídia tradicional ainda é muito arcaica, mantendo um oligopólio dos meios de comunicação de massa e mantendo uma agenda que é quase exclusivamente voltada para o mercado. Novos dispositivos de mídia são vistos como uma possibilidade de mudar isso e fazer com que a informação seja mais democrática, mas, ao mesmo tempo, o tipo de informação que as pessoas majoritariamente consomem nesses dispositivos não é muito crítico. Um exemplo disso é o fenômeno das fake news que ocorre no Brasil e, recentemente, interferiu em nossa eleição presidencial - assim como nos EUA. Como podemos fazer com que esses novos dispositivos de mídia sejam uma verdadeira ferramenta que produz informação de qualidade e contribui para a formação de uma visão de mundo crítica, principalmente em um país com um abismo social tão grande?

Mayer - Novamente, é sobre o processo de produção dessa informação. As pessoas se sentem atraídas por algo no qual veem sua comunidade, uma mídia comunitária vinda da comunidade. As questões são levantadas pela comunidade, as histórias são produzidas pela comunidade e a comunidade se reúne para assistir a essas produções. Podemos imaginar como as tecnologias globais podem fazer parte desse processo em vez de serem peças isoladas para consumo individual. Para que os novos meios sejam verdadeiramente populares, eles têm de ser consumidos dentro de algum processo coletivo. Eu não acho que uma mídia popular possa ser algo que você mesmo baixe em seu escritório. Quando vemos algo que gostamos em um ônibus e passamos para o nosso vizinho, estamos criando um circuito de mídia popular. Nós criamos circuitos populares da mídia todo o tempo. Não sou tão pessimista de pensar que nunca acontece nada na Globo, que não exista uma audiência de mídia popular crítica. Ontem à noite eu estava assistindo a Netflix... eu comecei a assistir a um filme chamado Temporada e a maior parte dele se passa nas favelas, na periferia de... não sei se é de Belo Horizonte ou de outra cidade. Até um programa comercial de alguma nova plataforma de mídia pode servir como um motivo para a comunidade se reunir e ter uma conversa crítica sobre a sua representação, sobre as questões que a afetam, mas não acho que uma mídia popular possa existir fora de uma conversação coletiva no espaço físico. Eu não acho que uma sala de bate-papo chega a um patamar de mídia popular, porque não é aberta, não é pública, as pessoas não precisam se expor cara a cara e olhar nos olhos umas das outras enquanto falam. O que a produção de vídeo popular fez foi trazer as pessoas para falarem sobre seus problemas, e uma crítica que eu teria sobre o vídeo popular hoje é que ele requer uma quantidade extraordinária de esforço e de tempo, algo que a maioria das pessoas não têm. Por isso, precisamos de outras maneiras de trabalhar com os horários 
das pessoas, trabalhar com a realidade de hoje - das pessoas que estão andando no ônibus, às vezes duas horas por dia - encontrando espaços para termos conversas como: "Quais são os problemas que nos afetam? Como estamos sendo representados? Como nós podemos nos autorrepresentar melhor e quais das nossas demandas estão caminhando para mudar a nossa representação, a nossa realidade?”. Não estou sugerindo que as coisas possam voltar a ser como eram. Temos que trabalhar com a realidade que temos. Há filmes independentes incríveis sendo produzidos, existem mídias locais maravilhosas sendo produzidas, mas eu não acho que nós tenhamos que ser produtores o tempo todo, há outras maneiras de participar.

Revista Intercom - É possível transformar esses dispositivos em ferramentas que ajudarão as pessoas a formar cidadania e criar uma visão de mundo crítica sem uma reforma na estrutura e na legislação dos nossos meios de comunicação de massa?

Mayer - Todas essas plataformas existem em uma economia de dados que depende da monetização e da comercialização de nossos dados privados. É preciso uma reforma com total transparência e controle sobre como nossas informações são coletadas através de algoritmos, através do armazenamento dessas informações e dos usos dessas informações. Essas são coisas que os governos nacionais deveriam regular. Há uma entrevista muito boa com um antigo executivo da Amazon, recém-publicada pelo Washington Post, na qual ele diz que ninguém deveria comprar a Alexa. Alexa é uma ferramenta de escutas telefônicas, é completamente monitorada, registra tudo. Se acreditarmos que algum governo não usará legalmente essa informação em algum momento, com objetivos políticos, somos idiotas, porque a Amazon não se preocupa com nossos dados pessoais, então precisamos pensar sobre a produção nesses dois níveis. Se você parar para pensar, o movimento na década de 1970 para uma Nova Ordem Mundial da Comunicação ${ }^{7}$ não era apenas por mais diversidade e pluralidade de conteúdos e reportagens, era também pela democratização da propriedade das estruturas de comunicação e pela existência de estruturas alternativas que atendessem aos interesses nacionais. Quando cinco empresas são detentoras da infraestrutura de dados do mundo e não se sentem suscetíveis a nenhum governo nacional, temos uma ameaça global.

Revista Intercom - No texto "Comunicação Comunitária e Educação para a Cidadania” (2002), traduzido por você em 2015 com o título "Civic Media, Meet Community Media (2015)”, Cicilia Peruzzo afirma que "na concepção liberal há uma individualização da cidadania [que] desaconselha a ação social e política" e ainda que "a conquista da cidadania significa a passagem de súditos para cidadãos, cujo arcabouço social requer o envolvimento das pessoas, condicionando-se seu status de cidadão à qualidade da participação”. O Brasil está em um momento político conturbado, com o cerceamento de vozes e direitos das minorias

7 Iniciativa do movimento dos Países Não-Alinhados, a Nova Ordem Mundial de Informação e Comunicação (NOMIC) é um projeto internacional que, desde o início dos anos 1970, no contexto da Guerra Fria, reivindica junto aos Estados governamentais e ao terceiro setor o reequilíbrio da distribuição dos fluxos globais de informação e comunicação entre os países desenvolvidos e subdesenvolvidos. Na mesma década, o projeto recebeu apoio da UNESCO. 
e uma clara individualização da cidadania. De quais maneiras a mídia comunitária deve se orientar nessa conjuntura social e política?

Mayer - Temos que lembrar que a mídia comunitária foi a resposta a uma época em que ninguém no Brasil usava a palavra cidadão. A mídia comunitária nunca se intitulou mídia cidadã, porque ser cidadão no Brasil é tipo uma maldição: “Ele é apenas um cidadão”, alguém que você não conhece, alguém com quem você não se importa. E assim a mídia comunitária foi uma mídia cidadã sem nunca usar a palavra cidadão. Ela foi a reação a um momento em que o Estado democrático tentava aumentar a participação (cidadã) e legitimar a ideia de que os cidadãos eram alguém que você conhecia. Eles eram seu irmão e sua irmã, portanto, eu creio que a mídia comunitária é a resposta à crise da dissolução dos direitos democráticos liberais na nossa sociedade. Ela é a cura da ameaça trazida pelo vírus do autoritarismo que ressurgiu nas sociedades estadunidense e brasileira. Quando falo que voltou à sociedade estadunidense, (quero dizer que) devemos lembrar que, no pós-Guerra Fria, o McCarthyismo era uma força autoritária com o intuito de conter a ideia de uma livre cidadania democrática, então temos ainda um legado de autoritarismo que a mídia comunitária pode remediar aumentando a participação no direito de comunicar.

Revista Intercom - Ao refletir sobre as formas de organização e modos de vida da população no cenário da globalização, Wolton (2004) escreve que "a abertura das fronteiras e a homogeneização dos modos de vida reforçam a necessidade de estar em algum lugar”. A mídia local e a mídia comunitária são importantes para os habitantes de bairros marginalizados e pequenas cidades do Brasil como ferramentas de identidade, memória, representação e reconhecimento na vida diária dessas pessoas. Como pensar a mídia comunitária diante das novas possibilidades de acesso a conteúdos transnacionais e da infinidade de materiais midiáticos que passaram a fazer parte do cotidiano da população mesmo nas cidades menores? Mayer - Isso é interessante porque sua pergunta não é apenas (sobre) como eu interpretei Dominique Wolton, que está dizendo que todos nós precisamos estar em algum lugar. O espaço comunitário vem do local, mas também podemos dizer que conteúdos globais podem ser locais quando inseridos em conversas e debates comunitários. Por exemplo, durante o desenvolvimento da Deep Dish Television, uma empresa de satélites lançada na década de 1990 para a transmissão de mídias alternativas e comunitárias, a ideia era globalizar coisas que vinham de um contexto e de um espaço muito local, no intuito de iniciar novas discussões em novos lugares e novos contextos, e algumas de suas programações eram extraordinárias. A programação inicial do Deep Dish era muito simples: a TV Paper Tiger escolhia professores de comunicação para ler o New York Times e comentar o que liam. Ou para ler revistas femininas: uma feminista lia revistas femininas, as suas matérias, as diferentes opiniões trazidas, e fazia uma crítica, mas tudo isso para oferecer um tema sobre o qual a comunidade pudesse discutir. O verdadeiro estopim para o início dos debates comunitários em escala global acerca da mídia alternativa ocorreu durante os protestos da Organização Mundial do Comércio em Seattle, em 1999, momento em que produtores de 
documentários, podcasters e fotógrafos começaram a reunir (conteúdos de) mídia sobre o que estava acontecendo nas ruas e publicar mundialmente na internet. Isso tornou-se um incentivo e um impulso para a localização de conflitos em torno de questões globais. O conflito de 1999 era decorrente das imposições de uma nova ordem comercial mundial que forçava os agricultores da Argentina a usarem os produtos da Monsanto, que forçava os cinemas a adquirirem mais filmes de Hollywood, que forçava a aplicação das leis de pirataria dos EUA na Nigéria... todas essas coisas estavam acontecendo: protestos globais, atores globais fazendo transmissões para discutir coisas como: “O que os nossos agricultores vão fazer? Que tipos de filmes temos que ver? Por que não somos informados pela mídia local sobre os protestos que estão acontecendo aqui?”. Nas mídias comunitárias essa noção de local é muito importante porque mostra que, se os problemas forem relevantes, eles se tornam locais através dos diálogos, independentemente de onde essas mídias são produzidas.

Revista Intercom - Halleck (2002), professora de Comunicação da Universidade da Califórnia em San Diego, afirma que a vida da maioria das pessoas nos EUA não está se tornando melhor. Podemos dizer o mesmo em relação à vida da maioria no mundo todo. Enquanto a desigualdade cresce, as corporações da mídia prosperam, em um descompasso entre um sistema técnico informacional e comunicativo controlado pelo Estado e mercado e o pouco espaço para a autonomia criativa e para a crítica do sistema capitalista. Ainda assim, Halleck (2002) expressa o potencial da mídia comunitária como forma de resistência. Você não acha que, mesmo sendo a mídia comunitária fundamental, falta-nos iniciativas para democratizar o acesso à diversidade da produção cultural na mídia hegemônica? No Brasil, qualquer blockbuster ocupa mais de 90\% das salas de cinema, sem nenhum respeito à legislação que estabelece 30\% das salas exibirem produção nacional.

Mayer - Por mais que Dee Dee Halleck tenha contribuído para as nossas perspectivas sobre mídia comunitária, o trabalho dela, a história dela está muito situada em um paradigma de mídia comunitária versus mídia de massa. Nossa realidade é frequentemente dividida em duas. Estruturalmente as corporações estão descentralizadas entre diversos parceiros que não são mídia de massa ou que não detêm todo o controle. As seis grandes distribuidoras globais dos filmes de Hollywood ainda dependem de pequenas produtoras, agências de publicidade e empresas de pesquisa de dados. Eu penso que a perspectiva de que tudo é ou grande e ruim ou pequeno e bom precisa ser problematizada porque, estruturalmente, essas corporações são descentralizadas e movidas por pessoas como nós, que também fazemos parte de comunidades em que nos envolvemos, nos engajamos e nos comunicamos. Então, definitivamente, precisamos apoiar políticas de privacidade, pela neutralidade das redes, pela proteção à autonomia criativa e aos direitos de propriedade intelectual. Ao mesmo tempo, temos que imaginar que, em certo sentido, nós nos democratizamos. A classe criativa não vive apenas em função da mídia de massa e de promovê-las. Trabalhadores criativos também estão participando de outros setores de interesse. É aí que o papel da Universidade pública 
se faz mais importante, no sentido de garantir que pessoas de diferentes origens sociais cheguem até as indústrias criativas, porque são elas que fazem essas conexões.

Revista Intercom - Sabemos que o vocábulo "comunidade” é de difícil categorização. Gostamos muito da noção do sociólogo norte-americano Sennet (2012), para o qual comunidade se define pela prática do compromisso de longo prazo, com base na obrigação, lealdade e/ou confiança, voltado para a cooperação coletiva. Quais são as referências teóricas que inspiram sua apreensão de comunidade?

Mayer: Amo o trabalho de Richard Sennet, mesmo. Ele é um intelectual público. Inclusive, a teoria dele sobre comunidade diz que toda inclusão também envolve exclusões e, para pessoas que são parte da comunidade, a definição daquilo que se tem em comum também é a definição daquilo que não pode fazer parte da comunidade. Considero que o processo de entender uma comunidade sempre se dá em relação a quem não pode fazer parte dela, a quem é excluído, às hierarquias internas que organizam a comunidade. Você pediu referências teóricas pessoais... Um teórico que sempre esteve presente comigo foi Raymond Williams, ao refletir sobre como as comunidades são materiais, mas, ao mesmo tempo, têm um sentimento estrutural que une as pessoas em torno de uma memória coletiva e de uma cultura coletiva. Essa é uma referência que sempre me interessou. Outra pessoa que me vem à mente, porque às vezes o conceito de comunidade é algo que pode ser ruim ou bom, é a Ida Klaus. Acho o recente trabalho de Ida Klaus sobre hegemonia muito interessante em relação ao populismo. Ida Klaus defende que o populismo é um termo que pode significar algo muito positivo ou algo muito negativo. Sempre é positivo para quem utiliza o termo. Ninguém usa (o termo) comunidade para dizer algo ruim, mas as designações desse termo dependem de quem o está utilizando e para quais finalidades.

Revista Intercom - Em sua pesquisa sobre a mídia como um dos modos a partir dos quais as pessoas podem voltar a se engajar nas questões políticas do Brasil, você faz uma distinção entre mídia comunitária e mídia alternativa, sendo a primeira aquela que "empodera as pessoas através das competências, tanto de liderança quanto as técnicas, necessárias para a autorrepresentação na esfera pública mediada” (MAYER, 2015). Entretanto, a mudança ocasionada pelas mídias sociais no início dos anos 2000, como você aponta, tem transformado o cenário das comunicações no Brasil através da propagação do acesso às novas mídias. Esse novo cenário complexificou as distinções entre mídia comunitária e mídia alternativa? Tomando por base a sua pesquisa, quais os desdobramentos dessa mudança no Brasil? Que desafios os pesquisadores brasileiros interessados nesse novo cenário podem vir a enfrentar?

Mayer - Penso que, em vez de falarmos mídia comunitária e alternativa, hoje em dia é realmente interessante falarmos sobre a mídia de Movimentos Sociais. Uma mídia que é, ao mesmo tempo, comunitária e uma alternativa de união a um movimento social: a 
comunidade de ativistas de mídia ecológica, a mídia do Black Lives Matter ${ }^{8}$, as novas vozes feministas e a mídia feminista, a mídia queer, a mídia trans ... todas são, ao mesmo tempo, (mídias) alternativas e comunitárias, então o termo, no século XXI, que parece estar mais em voga no Brasil, nos EUA, Grã-Bretanha, Hungria e Filipinas, são as mídias de Movimentos Sociais, que articulam vozes alternativas e formam uma espécie de comunidade voltada a questões relevantes para os membros dessa comunidade. Isso é o que aconteceu de mais novo e interessante recentemente, porque podemos conceber a mídia comunitária como aquela que operava em espaços geográficos, a (mídia) alternativa como aquela que operava em função dos tipos de conteúdo e das expressões alternativas à mídia de massa. O que vemos na mídia de Movimento Social é: um novo conceito de espaço e um novo conceito de discurso sendo propagado nas mídias sociais. Quero citar uma referência que considero interessante para os dias de hoje: o Marwan Kraidy, que escreveu um livro chamado The Naked Blogger of Cairo: Creative Insurgency in the Arab World ${ }^{9}$. A teoria dele a respeito das mídias e movimentos sociais diz que os produtores criativos online estão criando, fisicamente e nos conteúdos que produzem, um novo sentido para o corpo político. Por quê? Porque esses produtores possuem novas e diferentes representações sobre as pessoas, mas, ao mesmo tempo, estão colocando fisicamente os seus corpos em perigo. Nós achamos que os movimentos sociais acontecem no espaço público, mas se pensarmos no que está acontecendo em Hong Kong, não conseguimos distinguir a criação de mensagens online e o corpo político, do corpo real que está sentado (ao computador) ou se manifestando nas ruas. Acho que ele (Kraidy) tem uma teoria muito interessante sobre o quanto o corpo físico e o corpo representado são importantes para as políticas democráticas no contexto das mídias sociais. Acho que o desafio para os estudiosos da mídia é não esquecer o offline.

Revista Intercom - Quando você comenta, em sua entrevista para a Revista Compolítica, que ao entrevistar os trabalhadores das indústrias culturais, em geral, eles repetem a ideia de que estão indo muito bem no trabalho e as suas perspectivas de sucesso estão no caminho de serem alcançadas. Afirma ainda que "uma abordagem marxista seria pensar que eles têm consciência falsa, pois ignoram as condições materiais e de precariedade do mercado. Mas, atualmente, não é isso o que ocorre. Eles conhecem muito bem a precariedade. O problema é que, hoje em dia, você tem que abraçar a ideologia para avançar" (MAYER, 2016). Do que se trata essa ideologia? Como ela opera?

Mayer - As indústrias criativas e o trabalho criativo dependem do que eu chamaria de uma economia baseada na reputação, porque as indústrias criativas contratam pessoas como freelancers para trabalharem em equipe nos seus projetos. A melhor maneira de conseguir seu próximo emprego é dizer como tudo é maravilhoso na equipe e no projeto.

8 Black Lives Matter é um movimento ativista internacional, com origem na comunidade afro-americana, que campanha contra a violência direcionada às pessoas negras.

9 KRAIDY, M. The naked blogger of Cairo: creative insurgency in the Arab world. Harvard University Press, 2016. 
Por que os trabalhadores criativos não falam sobre sexismo, racismo ou discriminação em seus empregos? É porque isso não faria de você um bom colega de equipe e trabalhar em equipe significa suportar a dinâmica do grupo. Então, quem reproduz a ideia de que os profissionais da cultura serão todos delatores das suas próprias indústrias não é realista, porque toda essa economia se baseia no sigilo e na confiança entre os membros do grupo para que eles possam continuar trabalhando uns com os outros. Hoje em dia temos toda uma indústria só para limpar nosso Facebook, limpar nossos feeds do Twitter, garantir que aparentemos ser bons colegas de trabalho, portanto há muitos poucos espaços em nossas vidas privadas onde podemos ser autênticos, porque sempre estamos pensando no que outra pessoa vai pensar de nós. Nos tornamos um produto, estamos tentando vender nossa mão-de-obra a outros empregadores e às pessoas que trabalham conosco para que elas nos indiquem ao próximo emprego.

Revista Intercom - Segundo Eagleton (BOURDIEU; EAGLETON, 1996), poderíamos "presumir que existam tipos diferentes de legitimação, que vão desde uma internalização absoluta das ideias dominantes até uma aceitação mais pragmática ou cética” dessa ideologia. Gramsci, por sua vez, define essa aceitação como uma "consciência acrítica” (BURAWOY, 2010), ou seja, por mais que esses sujeitos saibam da sua condição de precariedade e dominação, ao mesmo tempo não conseguem sair da situação por não compreenderem como a ideologia dominante se conforma na estrutura das relações sociais. Portanto, se a noção de falsa consciência do marxismo já não explica a aceitação dessa ideologia, poderíamos pensá-la a partir das perspectivas de Eagleton (BOURDIEU; EAGLETON, 1996) e Gramsci (BURAWOY, 2010), segundo as quais haveria uma negociação em relação à dominação?

Mayer - Tenho que acreditar que todos temos dentro de nós uma capacidade crítica e o que devemos buscar como pesquisadores são maneiras de legitimar e permitir conhecimentos críticos sobre as realidades vividas pelas pessoas. Isso é o Freire (que diz), não o Gramsci ou o Eagleton. Penso que, no fundo, todos somos extremamente céticos a respeito da ideologia segundo a qual o Big Data é a solução de todos os problemas do mundo. Diante disso, o que precisamos fazer é fornecer informação que permita às pessoas refletir sobre essa ideologia. É interessante porque os especialistas em comunicação sempre pensam que mais comunicação resolverá os problemas do mundo, mas se pensarmos nisso, na economia de dados, mais comunicação na estrutura atual significa mais dados, significa que mais energia do mundo está sendo usada para resolver um problema que, na verdade, nós que estamos criando ao utilizarmos mais energia. Ultimamente tenho sido muito influenciada pelo trabalho de Mél Hogan e Asta Vanderau, que abordam o Data Center como um complexo industrial que mantém o que costumávamos chamar de complexo industrial militar, complexo industrial agrícola e complexo industrial-prisional. Hoje, todos eles estão sob a coordenação do complexo industrial do Big Data, o qual está criando o problema que pretende resolver. Ou seja, vivemos em um planeta cuja energia vai se esgotar e cujo clima vai se modificar de modo irreversível, mas, em vez de usarmos menos energia, sempre trazemos soluções que 
dependem da utilização de mais dados para resolver um problema que criamos por causa dos dados. Portanto, eu não acho que as pessoas sejam acríticas, mas nós, como estudiosos da comunicação, devemos oferecer informações que ajudem as pessoas a refletir sobre o que estamos fazendo quando pensamos que tudo o que precisamos é de mais soluções online. Acredito que todos nós temos muito a melhorar em relação ao nosso papel de divulgar esse conhecimento, e estou me incluindo nisso.

Revista Intercom - De novo uma romantização da comunicação como motor para a mudança...

Mayer - Sim. Eu não acho que os professores de Comunicação pensem o suficiente sobre produção de energia.

Revista Intercom - Sim. Você está pensando sobre a questão ecológica em um sentido muito amplo e é muito interessante o fato de vários autores estarem falando da ecologia da mídia. Claro, isso é debatido desde McLuhan e todos os seus discípulos, mas agora a ecologia da mídia é, em certo sentido, também um ponto de vista crítico, pelo menos para Muniz Sodré, não é?

Mayer - Quando McLuhan fala sobre a ecologia da mídia ele está pouco se importando com as relações de poder que conduzem essa ecologia. Vamos dar uma lida nos artigos de Robert Shiller sobre a produção de aparelhos de televisão no terceiro mundo para serem enviados ao mundo desenvolvido. Vamos dar atenção à geopolítica envolvida no fato de o "trabalho sujo" da mídia estar sendo feito por pessoas sem proteção de segurança, sem direitos trabalhistas e sem as condições sanitárias adequadas. A ideia de um ambiente midiático eficaz não é um conceito novo. As diferenças podem ser que, talvez agora, em alguns lugares, as pessoas estejam se tornando mais conscientes a respeito das condições análogas à escravidão enfrentadas pelos trabalhadores da Foxconn que constroem todos os iPhones do mundo. Jack Qiu chama isso de iSlavery. Nosso consumo desses celulares perpetua a destruição de meio ambientes e das condições de trabalho em lugares que não vemos porque não vivemos neles. Os consumidores não estão nos locais onde essas coisas são feitas. Portanto, se quisermos mesmo pensar em uma ecologia da mídia, não podemos esquecer a materialidade dos objetos, como eles são produzidos, por quem e sob quais condições.

Revista Intercom - Eu acho isso muito interessante, porque quando se fala em ecologia se fala de uma harmonia, e aqui está sendo usada uma metáfora completamente fora de propósito...

Mayer - Mas para os estudiosos críticos da comunicação isso sempre existiu. Eu acho que o McLuhan foi totalmente convertido. Ele começou como um estudioso crítico e se transformou em celebridade adotada por toda a mídia popular porque ele só falava com otimismo. Ele perdeu todo o seu senso crítico. 


\section{Referências}

ALINSKY, S. Rules for radicals: a practical primer for realistic radicals. New York: Vintage Books, 1971 BOURDIEU, P.; EAGLETON, T. A doxa e a vida cotidiana: uma entrevista. In: ZIZEK, S. Um mapa da ideologia. Rio de Janeiro: Contracampo, 1996.

BURAWOY, M. O marxismo encontra Bourdieu. Campinas: Editora da Unicamp, 2010.

FREIRE FILHO, J. Usos (e abusos) do conceito de espetáculo na teoria social e na crítica cultural. In: FREIRE FILHO, J; HERSCHMANN, M. (orgs.). Comunicação, cultura e consumo: a (des)construção do espetáculo contemporâneo. Rio de Janeiro: E-papers, 2005, p. 13-44.

HALLECK, D. Hand-held visions. The impossible possibilities of community media. New York: Fordham University Press, 2002.

KLEIN, N. Sem logo: a tirania das marcas em um planeta vendido. Rio de Janeiro: Record, 2002.

LASPADA, S. Grassroots Video and the Democratization of Communication: the case of Brazil. New York: Columbia University Teacher's College, 1992.

MAYER, V. For the People and By the People: TV Maxambomba's Regeneration of Popular Cinema. Studies in Latin American Popular Culture, v. 17, p. 223-232, 1998.

MAYER, V.; PERUZZO, C. Translation: civic media, meet community Media; Community Communication and Education for Citizenship. Critical Studies in Media Communication, v. 32, n. 3, p. 143-157, 2015.

MAYER, V. Estudos de produção e articulações de poder na Economia Criativa: pensando o local para compreender o global. Revista Compolítica, v. 6, n. 1, 2016.

OROZCO GÓMEZ, G. La condición comunicacional contemporánea. Desafíos latinoamericanos de la investigación de las interacciones en la sociedad red. In: JACKS, N. (org.). Análisis de recepción en América Latina: un recuento histórico con perspectivas al futuro. Quito-Ecuador: Editorial “Quipus”/ CIESPAL, 2011.

PERUZZO, C. Comunicação comunitária e educação para a cidadania. Revista Pensamento Comunicacional Latino-Americano, n. 1, out./nov./dez. 2002. São Bernardo do Campo: UMESP/Cátedra Unesco.

PROTZ, M. Distinguishing Between 'Alternative' and 'Participatory' Models of Video Production. In: THEDE, N.; ANBROSI, A. Video the Changing World. Black Rose Books, 1991.

SENNETT, R. Juntos: os rituais, os prazeres e a política da cooperação. Rio de Janeiro: Record, 2012.

WOLTON, D. A Outra Globalização. Edições Difel, 2004.

\section{Veneza Mayora Ronsini}

Professora Titular do Departamento de Ciências da Comunicação da UFSM e professora do Programa de Pós-Graduação em Comunicação. Pesquisadora PQ2 do CNPq. Coordena o grupo de pesquisa Usos Sociais da Mídia (CNPq). Estágio sênior na Nottingham Trent University (Inglaterra), com bolsa Capes. Doutora em Sociologia pela Universidade de São Paulo com bolsa-sanduíche (Capes) na University of California, USA. Mestre em Ciências da Comunicação pela Universidade de São Paulo. Graduada em Jornalismo pela Universidade Federal de Santa Maria (UFSM). Desde 2007, 
integra o Observatório Brasileiro de Ficção Televisiva. Coordenou o Acordo de Cooperação entre UFSM e Karlstad University (Suécia) de 2013 a 2017, com organização de seminário e workshop na Karlstad e seminário na Universidade de Estocolmo. Coordenou o GT Estudios de Recepción da ALAIC de 2009 a 2012; coordenou o GT de Recepção, Usos e Consumo Midiáticos da COMPÓS no período 2008-2009. Integrante do grupo CAPES-PrInt, como membro do projeto Informação e Tecnologias (2017-2022) contemplado no edital CAPES PrInt n. 41/2017. Temas de pesquisa: Mídia, classe social e gênero; Recepção e consumo do audiovisual; Consumo e identidades juvenis; Usos das tecnologias da comunicação e vida cotidiana; Tecnologias da comunicação e comunidades autossustentáveis; Etnografia crítica do consumo. E-mail: venezar@gmail.com.

\section{Laura Roratto Foletto}

Doutoranda em Comunicação pela Universidade Federal de Santa Maria e Mestre em Comunicação pelo mesmo programa. Graduada em Comunicação Social - Relações Públicas pela Universidade Federal de Santa Maria. É integrante do grupo de pesquisa Usos Sociais da Mídia (UFSM/CNPq). Temas de pesquisa: estudos culturais, recepção televisiva (telenovela), relações de gênero, interação, fãs, participação em rede, redes sociais, mídia e identidade, migrações, interculturalidade, mudança social, sustentabilidade, meio ambiente, comunicação para a mudança. E-mail: laura.roratto@ gmail.com.

\section{Marco Marão}

Doutorando em Comunicação pelo Programa de Pós-Graduação em Comunicação da Universidade Federal de Santa Maria (UFSM) e Mestre em Comunicação pelo mesmo programa. Graduado em Comunicação Social - Cinema Digital pela Universidade Metodista de São Paulo. É integrante do grupo de pesquisa Usos Sociais da Mídia (UFSM/CNPq). Temas de pesquisa: estudos de recepção e consumo midiáticos; usos de tecnologias de comunicação; comunicação e comunidade; comunicação para a mudança social; mídia e classe social; mídia e novos movimentos sociais; mídia e identidades juvenis; mídia e estudos de fãs. E-mail: marcomarao@gmail.com.

\section{Rafael Ferreira Medeiros}

Doutorando do Programa de Pós-Graduação em Comunicação da Universidade Federal de Santa Maria (UFSM). Mestre em Comunicação pela Universidade Federal de Ouro Preto (UFOP). Graduado em Comunicação Social - Jornalismo pela Universidade Federal de Minas Gerais (UFMG) e Publicidade e Propaganda pela Pontifícia Universidade Católica de Minas Gerais (PUC Minas). Membro do Grupo de Pesquisa Usos Sociais da Mídia (UFSM) e do Grupo de Pesquisa “Convergência e Jornalismo” (ConJor - UFOP). Programador de Rádio e Televisão na Universidade Federal de Minas Gerais (UFMG). Filiado à Associação Brasileira de Pesquisadores de História da Mídia (Alcar). Temas de pesquisa: mídia e comunidades autossustentáveis; recepção e consumo 
radiofônico; radiodifusão universitária; radiodifusão local; identidades e representações cotidianas. E-mail: rfmedeiros13@gmail.com.

\section{Mauricio Rebellato}

Mestrando em Comunicação pela Universidade Federal de Santa Maria. Pós-Graduado em Televisão e Convergência Digital na Unisinos. Bacharel em Comunicação Social - Jornalismo, pela Unicruz. Integrante do grupo de pesquisa Usos Sociais da Mídia, da Universidade Federal de Santa Maria. Repórter e editor da RBS TV Santa Maria. Temas de pesquisa: mídia, classe social, recepção e consumo do audiovisual. E-mail: mauricio-rebellato@hotmail.com.

\section{Lucas Reinehr}

Bacharel em Comunicação Social - Jornalismo pela Universidade Federal de Santa Maria. Foi bolsista de Ensino, Pesquisa e Extensão no Programa de Educação Tutorial da Comunicação, PETCom-UFSM de 2016 a 2019. E-mail: lucasreinehr@gmail.com.

Recebida em: 28.05.2020

Aprovada em: 15.10 .2020 